\title{
Variation in the measurements of basement membrane thickness and inflammatory cell number in bronchial biopsies
}

\author{
P. Sullivan*, D. Stephens**, T. Ansari*, J. Costello+, P. Jeffery*
}

\begin{abstract}
Variation in the measurements of basement membrane thickness and inflammatory cell number in bronchial biopsies. P. Sullivan, D. Stephens, T. Ansari, J. Costello, P. Jeffery. CERS Journals Ltd 1998.

ABSTRACT: We do not have an estimate of how much tissue is needed for a reliable measure of bronchial epithelial reticular basement membrane (RBM) thickness or for counts of inflammatory cells.

An assessment of the frequency distribution and variance of data from repeat measurements of RBM thickness and biopsy section inflammatory cell counts in cases with asthma $(n=6)$, chronic obstructive pulmonary disease (COPD; $n=5)$, and normal healthy subjects $(n=7)$ was made. Tissue sections were stained with haematoxylin and eosin or by immunohistochemistry for EG2, mast cell tryptase and CD3-positive cells.

Measurements of RBM thickness in individuals followed a log-normal distribution. For a precision of approximately $\pm 15 \%, 31-45$ measurements were required. In contrast, inflammatory cell counts for each individual did not follow a normal distribution. There was high variance such that the cumulative weighted mean did not become stable until at least $5-10 \mathrm{~mm}$ of tissue underlying the RBM had been included.

In conclusion multiple measurements of reticular basement membrane thickness or tissue section cell counts should be made for each individual in studies of bronchial biopsies. It is recommended that reticular basement membrane thickness should be measured at $20 \mathrm{~mm}$ intervals over a $1 \mathrm{~mm}$ reticular basement membrane length and that a zone beneath it of at least 5-10 mm of reticular basement membrane should be included for counts of inflammatory cells.

Eur Respir J 1998; 12: 811-815.
\end{abstract}

*Lung Pathology Unit, Asthma and Allergy Research Group, Imperial College School of Medicine at NHLI, London, UK. **Dept of Mathematics, Imperial College, London, UK. +Sackler Institute of Pulmonary Pharmacology, Dept of Respiratory Medicine, King's College Hospital Medical School, London, UK.

\author{
Correspondence: P. Jeffery \\ Lung Pathology Unit \\ Royal Brompton Hospital \\ Sydney Street \\ London SW3 6NP \\ UK \\ Fax: 441713518435
}

Keywords: Asthma

biopsy

bronchoscopy

chronic obstructive pulmonary disease variance

Received: January 151998

Accepted after revision June 301998
Inflammatory cells are present in the airways in asthma [1-4], and in smoking-related chronic obstructive pulmonary disease (COPD) [5-7]. In mild asthma the number of activated eosinophils and loss of surface epithelium correlates with airways hyperresponsiveness $[2,8,9]$ and thickening of the reticular basement membrane (RBM) is an early and characteristic histological feature [10] which may respond to treatment [11]. Homogeneous thickening of the RBM appears not to occur in chronic bronchitis and mild stable COPD [12]. Measures of its thickness may help, therefore, to discriminate between asthma and COPD, to determine whether treatment has significantly affected the thickness and to detect an asthmatic component in COPD [13]. These abnormalities can be detected in bronchial biopsies taken during flexible fibreoptic bronchoscopy, which has the advantage of direct access to the bronchial mucosa, the site of interaction between the environment and the host [14]. Biopsies can be taken from predetermined sites and samples can be taken before and after experimental allergen exposure or treatment. However, a potential disadvantage of the biopsy procedure is that the samples obtained are small and the distribution of inflammatory cells within them appears to be nonhomogeneous [15].

Whilst data have been reported elsewhere concerning the variation in inflammatory cells between subjects with asthma [16], between airway levels [7, 15] and between biopsies and within sections [17], there have been no reports of the variation between sections of a single biopsy. There is also no agreement as to how many measurements of the RBM should be made to obtain a reliable estimate of its thickness.

In order for any simple summary statistics or transformation of data to be informative, it is necessary to validate the common underlying assumption made in the analysis of such data. In the example of counts of inflammatory cells in biopsies it is necessary to establish that the cells are randomly distributed in the sections examined, as this will allow estimation of the area of tissue that should be inspected in order to obtain a mean with an acceptable confidence limit. Similarly, for measurements of thickness of the RBM, if multiple measurements from the same individual follow a familiar frequency distribution, knowledge of the variance may allow calculation of the amount of tissue required for a given degree of precision.

The objectives of the present study were: 1) to determine the data distribution of measurements of RBM thickness in order to estimate how many measurements are required per subject to obtain reasonable precision; 2) to describe the frequency distribution of counts of inflammatory cells in biopsies taken from an individual subject; 3) to determine whether the variance is similar in patients 
with the same or different airway conditions; and 4) to attempt to estimate the quantity of tissue that should be examined in future studies.

\section{Subjects and methods}

Biopsies were obtained for the purpose of this study from 18 subjects divided into three groups: 1) seven normal subjects, 2) six mildly atopic asthmatics, and 3) five patients with a clinical diagnosis of COPD (table 1). Normal and asthmatic subjects volunteered to take part in this study and COPD patients underwent biopsy for clinical purposes and gave informed written consent for the additional biopsies required for the present study. Normal subjects had no respiratory symptoms and a provocative concentration of methacholine causing a $20 \%$ fall in the forced expiratory volume in one second $(\mathrm{PC} 20)>16 \mathrm{mg} \cdot \mathrm{mL}^{-1}$; all were nonsmokers. Mild asthmatics had baseline forced expiratory volume in one second (FEV1) $>70 \%$ of predicted and were receiving only inhaled $\beta$-agonist as required. All but one were nonsmokers. The asthmatics had been diagnosed previously and had a documented history of asthmatic symptoms and PC20 methacholine of $<16 \mathrm{mg} \cdot \mathrm{mL}^{-1}$. Methacholine challenge was performed by timed tidal breathing via a calibrated Wright nebulizer [18]. Atopy was defined as a skin weal response $>3 \mathrm{~mm}$ above control to at least one of a bank of eight aeroallergens. The patients with COPD had an obstructive defect on lung function testing without reversibility to salbutamol and had a history of continuous breathlessness for $>1 \mathrm{yr}$, had smoked $>30$ pack-yrs and had had no exacerbation of bronchitis in the last 6 weeks [19]. One was a current smoker and two had smoked until 2 months before the study.

Approval for this study was obtained from the King's College Hospital Ethical Committee.

\section{Bronchoscopy}

Subjects received i.v. atropine and alfentanyl premedication and lignocaine was applied to the upper airway. Supplemental oxygen was administered and electrocardiogram (ECG) was monitored throughout. An Olympus FB-10 fibreoptic bronchoscope was used and biopsies were taken with cupped forceps (Olympus FB-1 9C, Keymed, Livingstone, UK) from the subcarina separating the left upper and lower lobe bronchi. Forceps were discarded after every fifth subject in order to maintain a sharp cutting edge.

\section{Biopsies}

Biopsies were fixed immediately in $2 \%$ paraformaldehyde, $\mathrm{pH} 7.4$ for $2 \mathrm{~h}$, transferred to $15 \%$ sucrose in phos-

Table 1. - Subject characteristics

\begin{tabular}{lccc}
\hline Group & $\begin{array}{c}\text { Age } \\
\text { yrs (range) }\end{array}$ & $\begin{array}{c}\text { FEV1 } \\
\% \text { pred (range) }\end{array}$ & $\begin{array}{c}\text { Smokers (within } \\
6 \text { months) }\end{array}$ \\
\hline Normal & $28(22-38)$ & $105(91-110)$ & $0 / 7$ \\
Asthma & $28(21-39)$ & $97(85-105)$ & $0 / 6$ \\
COPD & $67(63-71)$ & $42(31-65)$ & $3 / 5$
\end{tabular}

FEV1: forced expiratory volume in one second; COPD: chronic obstructive pulmonary disease. phate buffered saline (PBS) at $4^{\circ} \mathrm{C}$ for $24 \mathrm{~h}$, mounted in optimal cutting temperature (OCT; Merck, Leicester, UK) medium on cork, snap-frozen by plunging into melting isopentane previously cooled in liquid nitrogen [10] and then stored at $-70^{\circ} \mathrm{C}$. Sections $6 \mu \mathrm{m}$ thick were cut at $-20^{\circ} \mathrm{C}$ in a Bright cryostat (Cambridge, UK) and mounted on poly-L-lysine-coated glass microscope slides.

\section{Staining and immunohistology}

Sections were stained with either haematoxylin and eosin (H\&E) or an immunohistochemical technique applied to identify cells of distinct phenotype. The alkaline phosphatase/antialkaline phosphatase technique was used [20] in combination with mouse monoclonal antibodies directed against either EG2 (Pharmacia, Milton Keynes, UK 10-9196-01; 1:40 dilution), the secreted form of eosinophil cationic protein, to identify activated eosinophils, tryptase to identify mast cells (Dako, Ely, UK; AA1, M7052, 1:100 dilution) or CD3 for T-lymphocytes (Novocastra, Newcastle upon Tyne, UK; NCL-CD3-PS1; 1:50 dilution). New fushcin (Dako K698) was used as the chromagen conjugate and haematoxylin as the counterstain. Inflamed human tonsil was fixed and frozen similarly and included with each staining batch as a positive control.

In order to ensure that macrophages which had ingested apoptotic eosinophils or eosinophil products, a phenomenon which is described in vitro [21], were not forming part of the EG2+ cell count, dual staining with EG2 (1:20 dilution) and CD68 (Dako M0876; 1:25 dilution), a macrophage surface marker, was performed on selected sections from each subject. For dual staining, sections were incubated in $0.3 \%$ hydrogen peroxide in methanol for $20 \mathrm{~min}$ and then in $20 \%$ normal rabbit serum in Tris-buffered saline (TBS; Sigma, Poole, UK), pH 7.6, for $10 \mathrm{~min}$. The primary monoclonal mouse anti-CD68 in TBS with $10 \%$ normal human serum was added and incubated overnight at $4{ }^{\circ} \mathrm{C}$. Sections were then treated with biotinylated rabbit anti-mouse polyclonal immunoglobulin $\mathrm{G}$ (IgG) for 45 min, followed by avidin-biotin complex for $45 \mathrm{~min}$ and then diaminobenzidine (DAB) solution $(50 \mathrm{~mL}$ TBS, 50 $\mu \mathrm{L} \mathrm{30 \%} \mathrm{hydrogen} \mathrm{peroxide} \mathrm{and} 500 \mu \mathrm{L}$ DAB solution (Sigma): final concentration $25 \mathrm{mg} \cdot \mathrm{mL}^{-1}$ ). This was followed by cobalt chloride intensification. Sections were washed in TBS and treated with mouse monoclonal antibodies to EG2 for $1 \mathrm{~h}$ followed by rabbit anti-mouse IgG and then alkaline phosphatase-mouse anti-alkaline phosphatase complex with new fushcin as chromagen. Macrophages appeared black and EG2 positive material was red with a light-green counterstain [22].

\section{Quantification}

Reticular basement membrane thickness. RBM thickness was measured in randomly selected sections by image analysis of at least 30 points $20 \mu \mathrm{m}$ apart along the RBM of each section. The error of repeat measurement was assessed by multiple measurements $(n=30)$ of a single span of membrane in four subjects. In order to assess whether it was acceptable to define the perpendicular for measurement of RBM thickness by eye, image analysis was used to measure the angle between the operator-determined line 
of measurement and the true perpendicular to the outermost edge of the RBM (determined by a right-angle overlay placed on the computer screen at several points).

Inflammatory cell counts. Several sections (median number of sections $=8$, range 5-15) were counted for each cell type in each subject. Cell counts were all performed on coded slides by the same observer (P. Sullivan) using a $\times 40$ microscope objective. Cells were counted in a zone of tissue $60 \mu \mathrm{m}$ deep to the external limit of the epithelial RBM where there was no damage artefact. RBM length was measured by digital image analysis using Optilab 1.55 software (Improvision, Coventry, UK) with an Apple Macintosh computer and cell counts were expressed as cells.mm RBM length ${ }^{-1}$.

Analysis. Intraobserver reproducibility was expressed as single-occasion coefficient of variance for repeat measurements of RBM length, RBM thickness and cell counts. Deviation from perpendicular when measuring RBM thickness was used to calculate by trigonometry the consequent error to thickness measurement. Natural and $\log _{10}$-transformed data from each subject were tested for normality by Martinez-Inglewicz and D'Agostino tests of normality [23].

Modelling cell count data. We proposed that the cell count $n_{i j k l}$, for patient $i$ from category $j$, for cell type $k$, replicate section $l$ of length $d_{i j k}$, follows a Poisson distribution with rate parameter $c d_{i j k l}, k_{j k}$ (i.e., with the Poisson process parameter $k_{j k}$ depending only on patient category and cell type, in a section of area $c d_{i j k l}$, where $c$ is the constant width of the subepithelial band examined. A conventional model is to assume that $\log \left(k_{j k}\right)$ depends linearly and additively on the two factors: patient category and cell type (a log-linear model).

Using a standard statistical package (general linear interactive model (GLIM)), parameter estimates and goodnessof-fit statistics were obtained for such a model and the validity of the model for the present data was assessed (see AITKEN et al. [24] for details).

Data were also analysed descriptively. Weighted mean counts were calculated for each subject/cell marker by dividing the total cell count in all sections by the total RBM length examined. Cumulative weighted means were calculated as each additional section was counted. Data were analysed descriptively in the following ways. The proportion of single-section counts that were within $20 \%$ of the final weighted mean for each cell type in each individual was determined, and the number of sections and corresponding length of RBM that had been counted before the cumulative weighted mean was within $20 \%$ of the final weighted mean value was also established.

\section{Results}

\section{Reticular basement membrane thickness}

The intraobserver single-occasion coefficient of variance was $4 \%$ for RBM thickness. The angle of deviation from a true perpendicular of the outer limit of the RBM during measurement of its thickness was $3.7 \pm 2.7^{\circ}$ (mean \pm
SD). Calculation by trigonometry showed that the error introduced into the measurement of RBM thickness as a result was $0.2 \pm 0.15 \%$ (mean $\pm \mathrm{SD}$ ). Multiple measurements of RBM thickness at $20 \mu \mathrm{m}$ intervals conformed to a normal distribution after log transformation in 14/18 subjects and approximated log-normal in the remainder. The SD after log transformation was similar in all subjects and groups. Figure 1 shows data from three representative individuals, one normal, one asthmatic and one with COPD. It was calculated that to be $95 \%$ confident of a geometric mean within approximately $\pm 15 \%$ (i.e. between geometric mean $\times 1.15$ and geometric mean/1.15) required at least 40 measurements for each subject at intervals of $20 \mu \mathrm{m}$ along the RBM.

\section{Counts of inflammatory cells}

In total, 8,610 cells were counted along 790,500 $\mu \mathrm{m}$ of basement membrane from 608 sections. The intraobserver single-occasion coefficient of variance was $7 \%$ for counts of eosinophils (H\&E), 6\% for EG2, $6 \%$ for CD3 and $4 \%$ for tryptase-positive cells and $2 \%$ for RBM length. No cells stained with both EG2 and CD68 in bronchial tissue, whereas cells colocalizing these markers were found in the nasal polyps used as a positive control.

Inflammatory cell counts on multiple tissue sections from the same individual did not conform to a normal or log-normal distribution. Attempts to model Poisson rate parameters using a generalized linear model indicated that the data were overdispersed and that the Poisson model does not adequately describe the data. In addition, patients from the three groups were not sufficiently similar for the model to generate a general formula to predict the amounts of tissue required for analysis in asthma and COPD. The results for cell counts are, therefore, presented descriptively. In all groups there was a considerable degree of variance between sections from the same individual. Figure 2 shows data for $H \& E$ eosinophil counts from five of the six asthmatics (one asthmatic subject had no eosinophils in any of the sections examined). Less than onethird of all single-section cell counts were within $\pm 20 \%$ of

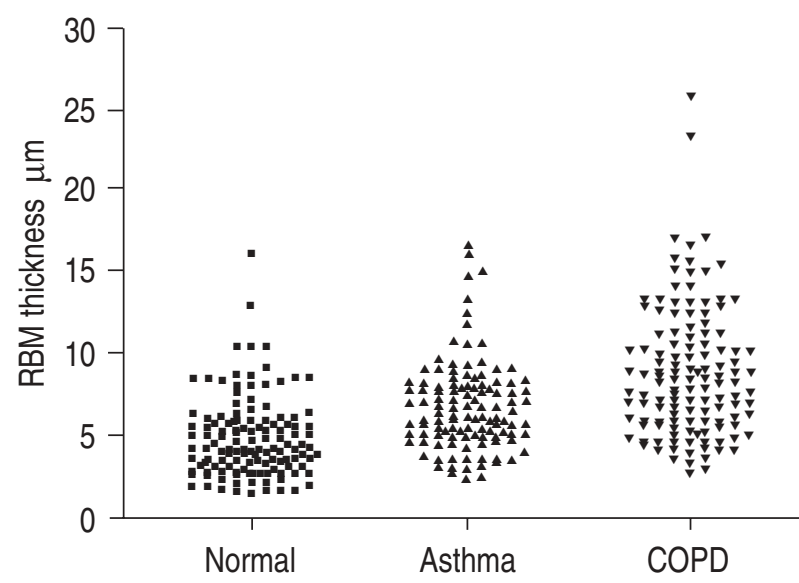

Fig. 1. - Multiple measurements of reticular basement membrane (RBM) thickness taken at $20 \mu \mathrm{m}$ intervals along the RBM from the same individual. Data shown are from three representative subjects, one normal, one asthmatic and one with chronic obstructive pulmonary disease (COPD). 


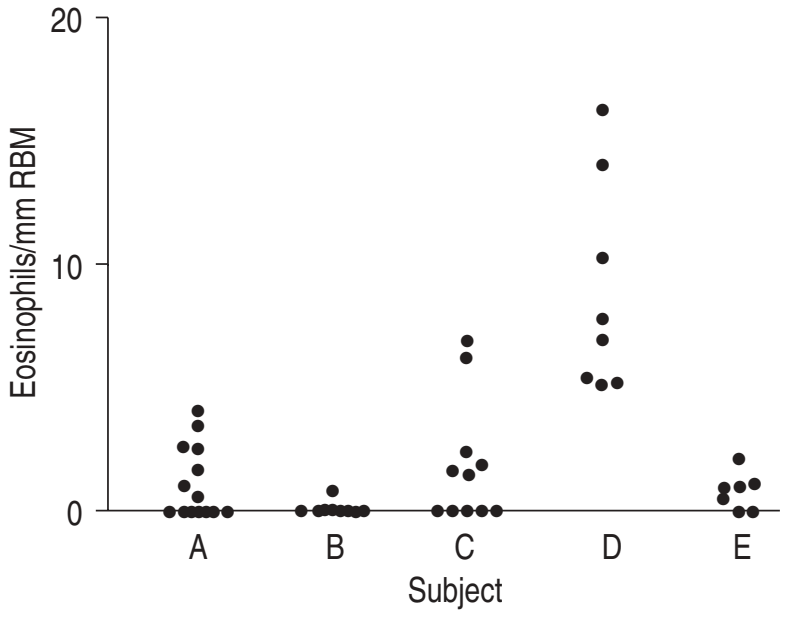

Fig. 2. - Eosinophil counts in several sections from the same individual for five mildly asthmatic subjects A-E (one asthmatic had no eosinophils in any sections). Each point represents a cell count from a single section. RBM: reticular basement membrane.

the final weighted mean value for the same individual. All subgroups were similar in this respect (asthmatics 25\%, COPD $30 \%$ and normals $33 \%$ of single sections) and there was no difference between cell types (eosinophils $26 \%$, mast cells $32 \%$, activated eosinophils $32 \%$ and T-lymphocytes $30 \%$ of sections). As a proportion of the final weighted mean, individual tissue section cell counts varied widely. Half of all series included single-section counts below $30 \%$ of the final weighted mean cell count for the individual and half included values above $150 \%$ of the final mean. In one-third of cases where the final weighted mean cell counts was greater than zero, cells were absent on one or more sections.

The quantity of tissue examined, expressed as the length of RBM and the number of sections examined before the cumulative weighted mean fell within $20 \%$ of the final value, is shown in table 2 .

\section{Discussion}

RBM thickness is increased in asthma and this measurement is of interest as it may be a consequence of the inflammatory process [25]. It was shown by light microscopy that measurements of RBM thickness are reproducible and that it is acceptable to judge the correct perpendicular for

Table 2. - Amount of tissue included in cumulative weighted mean before value fell within $20 \%$ of individual final weighted mean by patient group and individual cell type

\begin{tabular}{llc}
\hline & Median & 75th centile \\
\hline Asthma & $2(3.4)$ & $3(6.5)$ \\
Normal & $3(3.8)$ & $7(7.2)$ \\
COPD & $2(5.2)$ & $5(9.5)$ \\
Eosinophils & $5(3.9)$ & $8(6.7)$ \\
Mast cells & $2(2.8)$ & $3(5.1)$ \\
EG2+ & $4(4.8)$ & $7(7.2)$ \\
CD3 $^{+}$ & $2(2.9)$ & $3(3.4)$ \\
\hline
\end{tabular}

Values are given as number of sections counted with corresponding length $(\mathrm{mm})$ of reticular basement membrane in parentheses. COPD: chronic obstructive pulmonary disease. measurement by eye. Multiple measurements at intervals along the RBM vary considerably and this must be taken into account in future studies. On the basis of the present data it is recommended that at least 40 measurements are made per subject at an interval between measurements of $20 \mu \mathrm{m}$. This constitutes a total RBM length of $0.8 \mathrm{~mm}$ (one or two biopsy sections).

Flexible fibreoptic endobronchial biopsy is widely used for research into inflammation in airways diseases [14]. Biopsy has the benefit of allowing mild to moderate airway disease to be studied by directly sampling the airway mucosa and it has the distinct advantages that inflammatory cell density may be expressed in relation to a measured denominator such as tissue area or RBM length and biopsies can be taken repeatedly from a predetermined airway level. In contrast, there is no way of standardizing the level or extent of bronchial tree which is sampled by bronchoalveolar lavage or induced sputum. The advantages of biopsies are, however, offset by the variation which exists within the tissue sample. Whilst the variabilities between patients and between airway levels have been studied $[7,15]$ the variation within a biopsy has not. To the authors' knowledge the present study is the first to report within-biopsy variation and to provide an estimate of how much tissue should be sampled to provide reasonable precision. This will allow investigators to increase the power to detect differences between groups.

The present study has shown that multiple measurements of single-section cell counts for three cells implicted in the pathogenesis of asthma, i.e. eosinophils (as total or activated eosinophils), mast cells and T-lymphocytes $[26,27]$, do not follow a normal frequency distribution. If cells had been scattered randomly through the subepithelial tissue, the counts should have conformed to a Poisson distribution; however, this was not the present finding. The excess variance does not appear to be due to intraobserver variation in counting or measurement of RBM length or, in the case of EG2-positive cells, to the erroneous inclusion of macrophages which have ingested eosinophil products [21]. The likely explanation is that cells are clustered within airway tissue. As a consequence the number of sections needed for a given degree of precision could not be predicted. In descriptive terms, counts of single sections appear to be imprecise and only a minority fall within $20 \%$ of the value derived from counts of several sections of a relatively large amount of tissue. Approximately two-thirds of the counts fall very wide of this value. In order to improve the power of studies designed to detect differences in inflammatory cell numbers between subject groups it is preferable to count multiple biopsy sections. In the present study the median number of biopsy sections required before the cumulative weighted mean result was within $20 \%$ of the final result was two. This is encouraging but means that the value was above two in half of all cases studied. The 75th centile was six sections (representing $7.8 \mathrm{~mm} \mathrm{RBM}$ length), which means that in one quarter of cases the amount of tissue required was greater than six sections.

To date, many biopsy studies have recorded counts of a relatively small amount of tissue for each cell type [2830]. It is important to note that the findings of the present study do not diminish the validity of significant differences between groups already demonstrated in such studies, since these differences can be regarded as having been 
detected in spite of the relatively high variance in the data. However, in view of the present findings, it is recommended that larger numbers of sections be included to enable a more precise calculation of the mean for each cell type. This would have the effect of improving the power of future studies to detect differences between patient or subject groups.

In conclusion, larger numbers of tissue sections should be assessed in biopsy studies. Approximately 1,000 $\mu \mathrm{m}$ of reticular basement membrane measured at $20 \mu \mathrm{m}$ intervals was associated with a calculated precision of $15 \%$ for reticular basement membrane thickness. Unfortunately, the present data show that it is not as yet possible to predict the amount of tissue required for such precision of inflammatory cell counts, but descriptive analysis suggests that at least six sections or a zone beneath $7 \mathrm{~mm}$ of the reticular basement membrane should be included per cell type.

\section{References}

1. Azzawi M, Bradley B, Jeffery PK, et al. Identification of activated $\mathrm{T}$ lymphocytes and eosinophils in bronchial biopsies in stable atopic asthma. Am Rev Respir Dis 1990; 142: 1407-1413.

2. Beasley R, Roche W, Roberts JA, Holgate ST. Cellular events in the bronchi in mild asthma and after bronchial provocation. Am Rev Respir Dis 1989; 139: 806-817.

3. Azzawi M, Johnston PW, Majumdar S, Kay AB, Jeffery PK. T lymphocytes and activated eosinophils in asthma and cystic fibrosis. Am Rev Respir Dis 1992; 145: 1477-1482.

4. Djukanovic R, Roche WR, Wilson JW, et al. Mucosal inflammation in asthma. Am Rev Respir Dis 1990; 142: 434-457.

5. Saetta M, Di Stefano A, Maestrelli P, et al. Airway eosinophilia in chronic bronchitis during exacerbations. Am J Respir Crit Care Med 1994; 150: 1646-1652.

6. Turato G, Di Stefano A, Maestrelli P, et al. Effect of smoking cessation on airway inflammation in chronic bronchitis. Am J Respir Crit Care Med 1995; 152: 1262-1267.

7. O'Shaughnessy TC, Ansari TW, Barnes NC, Jeffery PK. Inflammation in bronchial biopsies of subjects with chronic bronchitis: inverse relationship of CD8 + T lymphocytes with FEV1. Am J Respir Crit Care Med 1997; 155: 852-857.

8. Jeffery PK, Wardlaw A, Nelson FC, Collins JV, Kay AB. Bronchial biopsies in asthma. An ultrastructural quantitative study and correlation with hyperreactivity. Am Rev Respir Dis 1989; 140: 1745-1753.

9. Bradley BL, Azzawi M, Jacobson M, et al. Eosinophils, Tlymphocytes, mast cells, neutrophils and macrophages in bronchial biopsies from atopic asthmatics: comparison with atopic non-asthma and relationship to bronchial hyperresponsiveness. J Allergy Clin Immunol 1991; 88: 661-674.

10. Roche WR, Beasley R, Williams JH, Holgate ST. Subepithelial fibrosis in the bronchi of asthmatics. Lancet 1989; i: 520-523.

11. Olivieri D, Chetta A, Del Donno M, et al. Effect of short term treatment with low dose inhaled fluticasone propionate on airway inflammation and remodelling in mild asthma: a placebo controlled study. Am J Respir Crit Care Med 1997; 155: 1864-1871.

12. O'Shaughnessy TC, Ansari TW, Barnes NC, Jeffery PK. Reticular basement membrane thickness in moderately severe asthma and smokers' chronic bronchitis with and without airflow obstruction (Abstract). Am J Respir Crit Care Med 1996; 153: A879.
13. Chanez P, Vignola AM, O'Shaughnessy T, et al. Corticosteroid reversibility in COPD is related to features of asthma. Am J Respir Crit Care Med 1997; 155: 1529-1534.

14. Jeffery PK. Bronchial biopsies and airway inflammation. Eur Respir J 1996; 9: 1583-1587.

15. Azzawi M, Bradley B, Jeffery PK, et al. Coefficients of variation for counts of cellular infiltrate in bronchial biopsies in normal and asthmatic subjects (Abstract). Am Rev Respir Dis 1990; 141: A500.

16. Richmond I, Booth H, Ward C, Walters EH. Intrasubject variability in the airway inflammation in biopsies in mild to moderate stable asthma. Am J Respir Crit Care Med 1996; 153: 899-903.

17. Sont JK, Willems LNA, Evertse CE, Hooijer R, Sterk PJ, van Krieken JHJM. Repeatability of measures of inflammatory cell number in bronchial biopsies in atopic asthma. Eur Respir J 1997; 10: 2602-2608.

18. Cockcroft DW. Measurement of airway responsiveness to inhaled histamine or methacholine; method of continuous aerosol generation and tidal breathing inhalation. In: Hargreave FE, Woolcock AJ, eds. Airway Responsiveness: Measurement and Interpretation. Mississauga, Astra Pharmaceuticals Canada, 1985; pp. 22-28.

19. A Consensus Statement of the European Respiratory Society. Optimal assessment and management of chronic obstructive pulmonary disease (COPD). Eur Respir $J$ 1995; 8: 1398-1420.

20. Mason DY, Sammons R. Alkaline phosphatase and peroxidase for double immunoenzymatic labelling of cellular constituents. J Clin Pathol 1978; 31: 454-460.

21. Stern M, Meagher L, Savill J, Haslett C. Apoptosis in human eosinophils. Programmed call death in the eosinophil leads to phagocytosis by macrophages and is modulated by IL-5. J Immunol 1992; 148: 3543-3549.

22. Hsu SM, Soban E. Color modification of diaminobenzidine precipitation by matalic ions and its application for double immunohistochemistry. J Histochem Cytochem 1997; 30: 491-493.

23. Martinez J, Ingelwicz B. A test for departure from normality based on a biweight estimate of scale. Biometrika 1981; 68: 331-333.

24. Aitken M, Anderson D, Francis B, Hinde J. Statistical modelling in GLIM. Oxford, Oxford Scientific Publications, 1990.

25. Brewster CEP, Howarth PH, Djukanovic R, Wilson J, Holgate ST, Roche WR. Myofibroblasts and subepithelial fibrosis in bronchial asthma. Am J Respir Cell Mol Biol 1990; 3: 507-511.

26. Bradding P, Roberts JA, Britten KM, et al. Interleukin-4, -5 , and -6 and tumor necrosis factor- $\alpha$ in normal and asthmatic airways: evidence for the human mast cell as a source of these cytokines. Am J Respir Cell Mol Biol 1994; 10: 471-480.

27. Ohashi Y, Montojima S, Fukuda T, Makino S. Airway hyperresponsiveness, increased intracellular spaces of bronchial epithelium, and increased infiltration of eosinophils and lymphocytes in bronchial mucosa in asthma. Am Rev Respir Dis 1992; 145: 1469-1476.

28. Lundgren R, Soderberg M, Horstedt P, Stenling R. Morphological studies of bronchial mucosal biopsies from asthmatics before and after ten years of treatment with inhaled steroids. Eur Respir J 1988; 1: 883-889.

29. Foresi A, Bertorelli G, Pesci A, Chetta A, Olivieri D. Inflammatory markers in bronchoalveolar lavage and in bronchial biopsy in asthma during remission. Chest 1990; 98: 528-535.

30. Sullivan PJ, Bekir S, Jaffar Z, Page C, Costello J. Antiinflammatory effects of low dose oral theophylline in atopic asthma. Lancet 1994; 343: 1006-1008. 